\title{
Regional Governance and Sustainability: Research towards evidence- based policy making, at the Region of Crete
}

\author{
Nikos Papadakis \\ Professor, Director of the Centre for Political Research and Documentation (KEPET), \\ Department of Political Science, Deputy Director of the Centre for Research \& Studies of the \\ University of Crete (UCRC), University of Crete, Rethymnon, Greece
}

\author{
Kostas A. Lavdas \\ Professor, Department of International, European and Area Studies, \\ Panteion University of Athens, Greece \\ Dimitrios Kotroyannos \\ Professor, Director of the Centre for Human Rights (KEADIK), \\ Department of Political Science, University of Crete, Rethymnon, Greece
}

\section{Stylianos Ioannis Tzagkarakis}

Postdoctoral researcher and researcher of the Centre for Human Rights (KEADIK), Department of Political Science, University of Crete, Rethymnon, Greece

\section{Apostolos Kamekis}

PhD School of Medicine, University of Crete, Researcher of the Centre for Human Rights (KEADIK), Department of Political Science, University of Crete, Rethymnon, Greece

\section{Maria Drakaki}

PhD Candidate and researcher of the Centre for Political Research and Documentation (KEPET), Department of Political Science, University of Crete, Rethymnon, Greece

\section{ABSTRACT}

It is widely accepted that sustainable regional development can only be achieved if the concept of sustainability is strongly connected with innovation and improvement of regional governance. This task is extremely important yet demanding as long as several policy levels and areas are interconnected as well as it is crucial to equally reinvigorate the basic pillars of sustainable development, namely economy, society and the environment. Thus, in order to conclude if the basic prerequisites exist and whether there are dynamics, drawbacks as well as opportunities in the regional level, it is important to conduct research concerning the above-mentioned connected policy areas, notions and concepts. This paper aims to analyze the basic outcomes of a largescale qualitative and quantitative research that was conducted in the region of Crete in Greece, in order to categorize the problems, challenges, opportunities and drawbacks that regional governance, encounter and propose ways-directions in order to overcome them and achieve a socially, economically and environmentally viable future.

Keywords: Regional governance; sustainability; innovation; evidence- based policy making, regional development. 


\section{INTRODUCTION}

Sustainability, regional development and innovation are three interconnected concepts which include several fields of policy implementation. At the same time, these concepts underline the importance of regional governance in terms of implementing policies that respect the sustainability values-pillars, namely environment, economy and society [1]. It turns out that the concept of sustainability has been introduced in the public discourse during the 1960s under serious concerns about the rising environmental problems [2]. Over the years and in the light of the changes that have been a result of the rapid industrialization and the transformation of the society into a highly consumerist one, the need for further protection of natural resources has emerged $[3,4,5,6]$. It should be noted that sustainable development is directly connected with regional development and its objective is the creation of sufficient, innovative economies which will offer welfare conditions for their citizens. Therefore, it is crucial for the local and central authorities to create the conditions that will encourage research and entrepreneurship.

The main aim of this paper is to present some of the basic outcomes of a large- scale research, conducted in the region of Crete, Greece in 2016 by the Centre for Political Research and Documentation (KEPET) and the Centre for Human Rights (KEADIK) of the Department of Political Science of the University of Crete, within the framework of the Research Project entitled "Governance, Sustainability and Regional Innovation", funded by the Region of Crete (KA 4289, Team Leader: Professor Nikos Papadakis, Duration: 19 October 2015- 18 April 2018). The first part of the paper comprises a brief analysis of the theoretical dimensions taken into account for the conduction of the research. In the second part an analysis of the basic outcomes of the quantitative and qualitative research that was conducted in Crete is presented followed by the presentation of the basic proposals and conclusions. The main aim is to stress the importance for intervention in specific sectors of the local society, economy and administration in order to effectively address the existing problems and to enhance development and innovation. The opinion of the citizens as well as the opinion of institutional actors' representatives are considered decisive in investigating the basic parameters of regional development, sustainability and innovation along with the prospects for improvement and amelioration in the three sustainability pillars (economy, society, environment) in the local level (region of Crete) during the current recession period.

\section{THEORETICAL INSIGHTS ON SUSTAINABILITY, REGIONAL DEVELOPMENT AND GOVERNANCE}

From the initial emergence of the inherent human desire to construct and systematically participate in organized collective structures, the necessity for their conscious formation and for reaching different ways of their governance arose. Unavoidably, although "governance" as a term is used to a large extent in the articulation of political discourse, it therefore emphasizes on issues in both central and regional-local state administration [7]. However, it is difficult to clearly define a generally acceptable and completely specific definition for governance. This formulation is reinforced by the review of the international literature, where it is evident that the term "governance" contain a conceptual diversity $[8,9]$. However, political science has tried to "delimit" this concept by using it in order to highlight the institutional and / or informal impact of various social and economic factors in the policy process [10] as well as for demonstrating the numerous transformations of the ways that political decisions are made. Thus, political decisions are the result of the dialectical negotiation between state (government) and private actors, and the emergence of new ways of governance [11], based on three main pillars; responsibility, transparency and participation [12]. 
However, over the decades and with the successive changes that have taken place in the globalized "society", from the early industrial period to the late industrialization and then to the age of digitization and automation, the need for modernization of the governance models is evident. In this respect, the notion of "sustainability" plays an important role. Recognizing its catalytic role, the European Union (EU) recently has included it at the core of the European policy guidelines, as long as sustainability contributes decisively to growth as well as to social and economic well-being, along with the necessary emphasis on environmental protection.

As it has been already stated, the concept of sustainable development is based on three mutually reinforcing and interconnected pillars; the environmental, the economic and the social. The key features of the environmental pillar focus on maintaining a stable basis for managing environmental resources, avoiding their over-exploitation as well as enhancing renewable energy systems, but having as a key point the preservation of biodiversity and respect of the natural ecosystem. Correspondingly, the characteristics of the economic pillar include the production of products and services on a lasting basis, while it emphasizes on efforts in order to enhance social justice, without, however, hampering the functioning of the free market. In terms of the social pillar, in order for a system to be socially sustainable, a fair distribution should be achieved, with equal opportunities to social goods, opportunities and services for all citizens $[4,5,13,14]$.

In this context of reforming the new governance models, the regional institutions, which emerge as an active and central factor of economic development and political intervention, play a predominant role $[9,15]$. The shift, which include efforts in order to strengthen the decentralized administration, contributes to the activation of the regions in order to promote innovation within the international competitive environment, with the upper aim of cultivating competitive advantages that bring about positive economic, environmental and social outcomes. Therefore, innovation plays a key role in regional development as it contributes to the enhancement of the interconnection between technology, private actors and regional institutions, with focus on promoting new technologies and developing relevant skills $[9,16]$.

Based on the above-mentioned, it turns out that sustainable development is directly linked with regional development, aiming at economic growth and the achievement of regional innovation. This makes necessary the cultivation of those conditions that will contribute to the creation of wider systems that will encourage innovation, research and entrepreneurship. The EU plays a key role in this strategy through the implementation of the "Innovation Union" initiative in the context of the new European Strategy. This EU support is reflected in the funding of $€ 69.8$ billion for the period 2014-2020 for smart growth, including regional development, employment, research, energy and transport networks, education and training, € 62.5 billion for sustainable development and natural resources, including agriculture, rural development and the environment [17], and $€ 65.5$ billion for the promotion of innovation (Figure 1). However, as reflected in Figure 2, Greece is in the last positions among EU countries in relation to the funds spent on innovation and research, and therefore the need for the design and implementation of a political strategy that will support innovation and research in order to provide a springboard for economic growth and consequently on social prosperity, is highly eminent. 
Figure 1: General European Funding per Sector: Research and Innovation
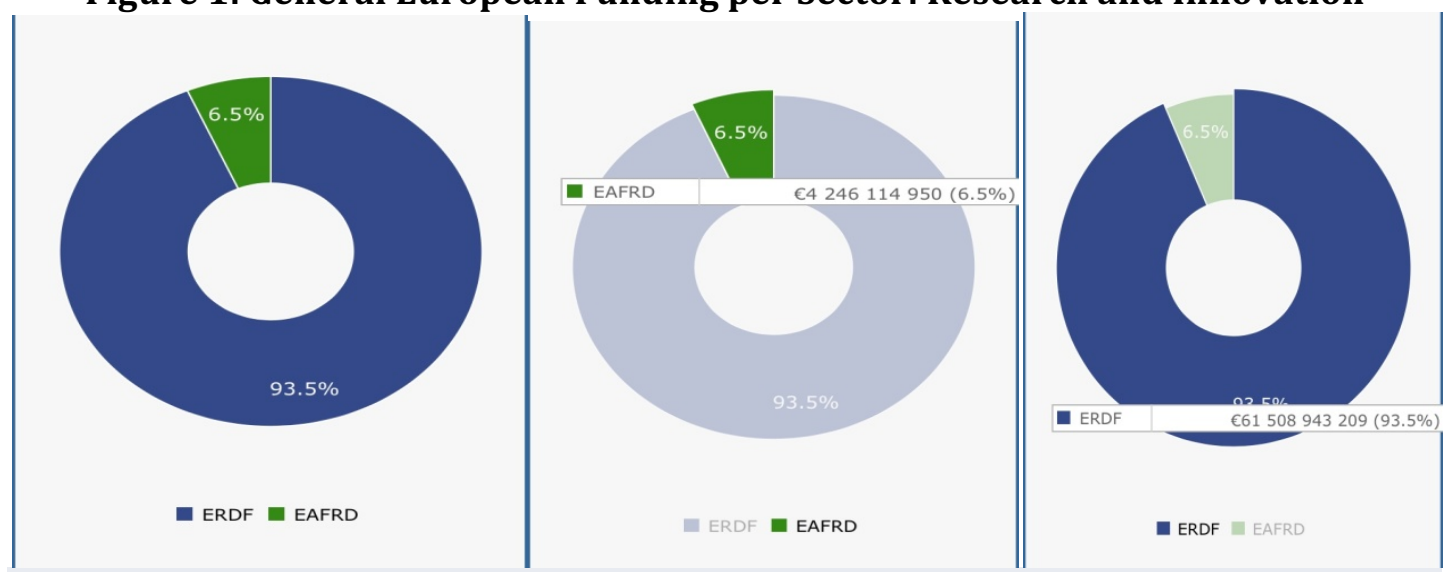

Source: European Commission data on General Funding on Research and Innovation (2017). Available online at: http://ec.europa.eu/regional_policy/el/policy/themes/researchinnovation/.

Figure 2: General Funding per Member State: Research and Innovation (billion $€$ )

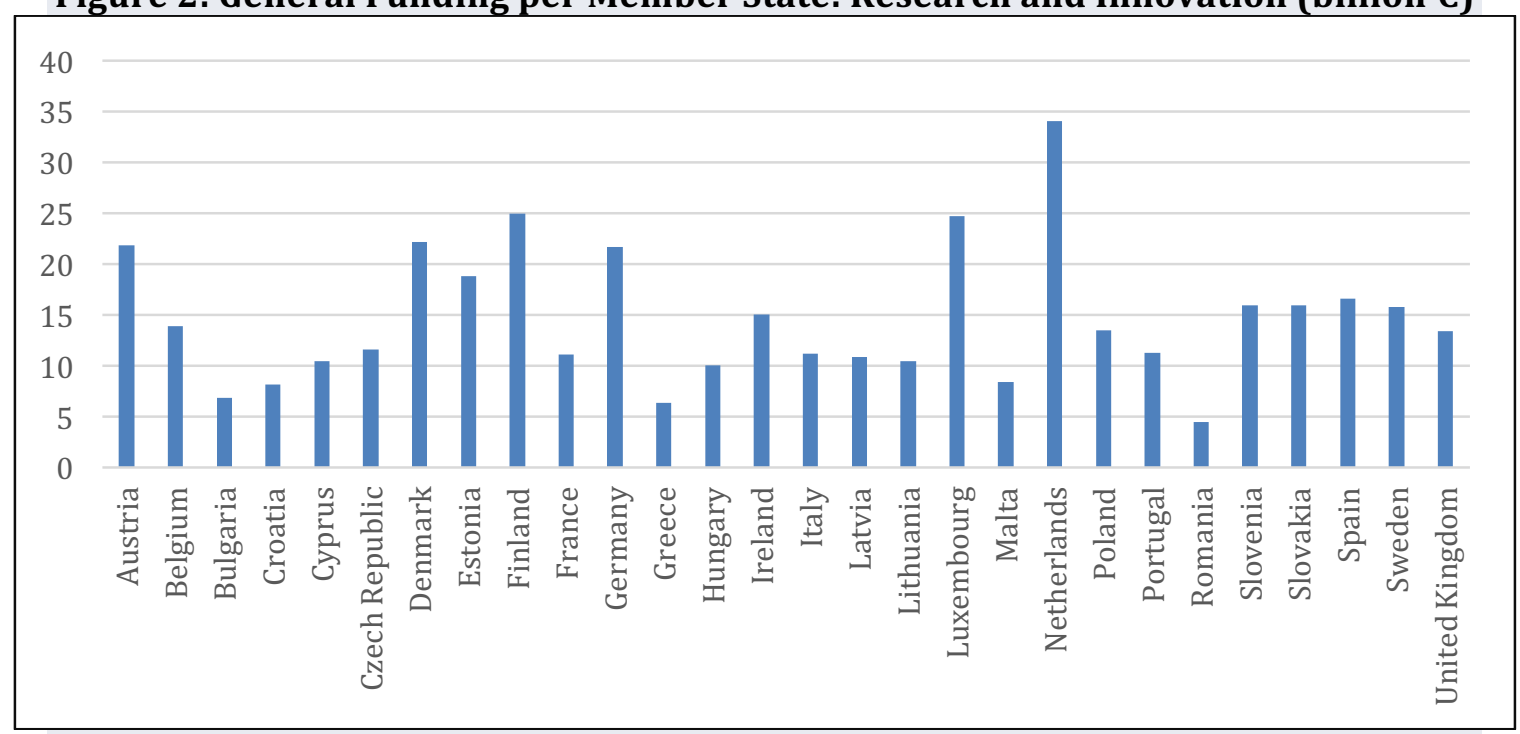

Source: European Commission data on General Funding on Research and Innovation (2017). Available online at: http://ec.europa.eu/regional policy/el/policy/themes/researchinnovation/.

\section{AIM OF THE STUDY}

Based on the above-mentioned theoretical considerations, a research project was designed by the Centre for Political Research and Documentation (KEPET) and the Centre for Human Rights (KEADIK) of the Department of Political Science of the University of Crete, in order to study the parameters, connections and dimensions of sustainability and regional governance at the region of Crete, Greece. The main objective of the project was to investigate the multidimensional interaction between governance models and sustainability as well as to produce new knowledge for sustainable development and governance through empiricallybased planning of higher education (Proposed Postgraduate Studies) and training (Training Program for Local Government Executives) based on the needs assessment and the development of empirically based policy proposals, focusing on seven main pillars: 1. Political Stability and Quality of Regulatory Mechanisms, 2. Efficiency of Governance, 3. Sustainable Development and Environmental Protection, 4. Social Policy and Improved Insurance Systems, 5. Determinants of Sustainability, 6. Sustainable Development, Agricultural Products and Public Health, 7. Tourist Product and Development in Crete. This paper includes a tentative analysis of the basic outcomes of this large research process. 


\section{RESEARCH METHODOLOGY}

The diagnosis of the needs and shortcomings at the level of the Region of Crete in the abovementioned areas of sustainability, regional governance and innovation contributes to the optimal establishment of research-oriented policy proposals aimed at promoting sustainable regional development, which is expected to contribute further to the improvement of living conditions and to develop principles such as environmental protection and sustainability, which are necessary for the realization of the above-mentioned pillars of regional development. This particular investigation, which was based on both secondary quantitative and primary qualitative and quantitative research \{through a triangular methodological strategy (qualitative research-diagnosis of needs and two quantitative surveys)\}, allowed the export of reliable and useful conclusions that led to the development of policy proposals, which attempt to meet the needs of the Region, aiming to offer innovative development solutions. The latter are expected to improve the state of affairs in the Region of Crete, contributing effectively to addressing existing problems and identified needs.

The first quantitative research aimed to evaluate and prioritize the policy strategies of the Region of Crete in the areas of Health, Environment and Agricultural Policy. It was conducted through telephone interviews using the C.A.T.I. system [18] (Computer Aided Telephone Interviewing) based on a structured electronic questionnaire [19]. The interviews were conducted on both men and women, residents of Crete, aged above 18 years old. The sample size was $n=600$ interviews and was representative of the population, based on the 2011 census, with proportional distribution to the Municipalities and Regional Prefectures of Crete. Both the citizens' satisfaction with existing policies and the current situation, as well as the degree of priority that citizens attach to each of the different axes of the sectoral policy strategies, have been addressed as continuous variables and an 11-point Likert scale (0-10) was used [20].

The second quantitative research aimed to evaluate the policy strategies of the Region of Crete in the area Tourism. It was conducted through telephone based on a structured electronic questionnaire [19]. The interviews were conducted on both men and women, residents of Crete, aged above 18 years old. The research was conducted in three phases and the total sample size was $n=2925$ interviews. It was representative of the population, based on the 2011 census, with proportional distribution to the Municipalities and Regional Prefectures of Crete.

The qualitative research was conducted in institutional representatives of Crete and included 16 semi-structured as well as 4 narrative interviews (four per semi-structured and one narrative interview per Regional Prefecture). The questionnaire of the semi-structured interviews included five topics (introductory remarks, biographical details, regional development issues, regional governance issues and the concluding remarks) and forty one questions. Both semi-structured and narrative interviews aimed at identifying the opinions, challenges, drawbacks, proposals and good practices from the regional policy makersinstitutional actors' representatives in the fields of regional governance, sustainability, innovation and regional development prospects.

\section{KEY RESEARCH FINDINGS: DETERMINANTS, DIMENSIONS AND PRIORITIES OF REGIONAL POLICY AT CRETE, DURING THE CRISIS}

The economic crisis that hit the global economy has left its most visible impact, especially in the countries of southern Europe. Greece is a prime example, as it has been hit harder by the financial crisis and is still in recession. On the basis of the available statistics, the impact of the economic downturn is clearly reflected in rising unemployment rates, and in particular youth unemployment, as well as a significant reduction in citizens' income and, consequently, the 
deterioration of their living standards [21]. This combination is a stepping stone to maximizing the risk of poverty and social exclusion, particularly among vulnerable social groups, while increasing the difficulty of implementing public policies at the central and regional level. Therefore, it should be noted that the implementation of central and regional policies has been greatly influenced by budget cuts, resulting in a reduction of the ability to meet the specific needs of local communities. Therefore, it is evident that in various public policy levels the satisfaction of the citizens in Crete is negative.

Citizens and representatives of regional institutional actors, although generally satisfied with Regional Governance at Crete (as evidenced by quantitative and qualitative research), are still experiencing the consequences of the crisis and the frequent failure of the Central State to respond effectively to their needs, especially regarding major social services. In this respect, with regard to health policy issues (which essentially involve policy design and implementation at central level), there is a significant lack of prevention policies and insufficient provision of primary health care. At the same time, satisfaction with the quality of health services and facilities is particularly low, while high individual participation costs are a basic constraint for addressing health needs.

Figure 3: Citizens' satisfaction index on health care

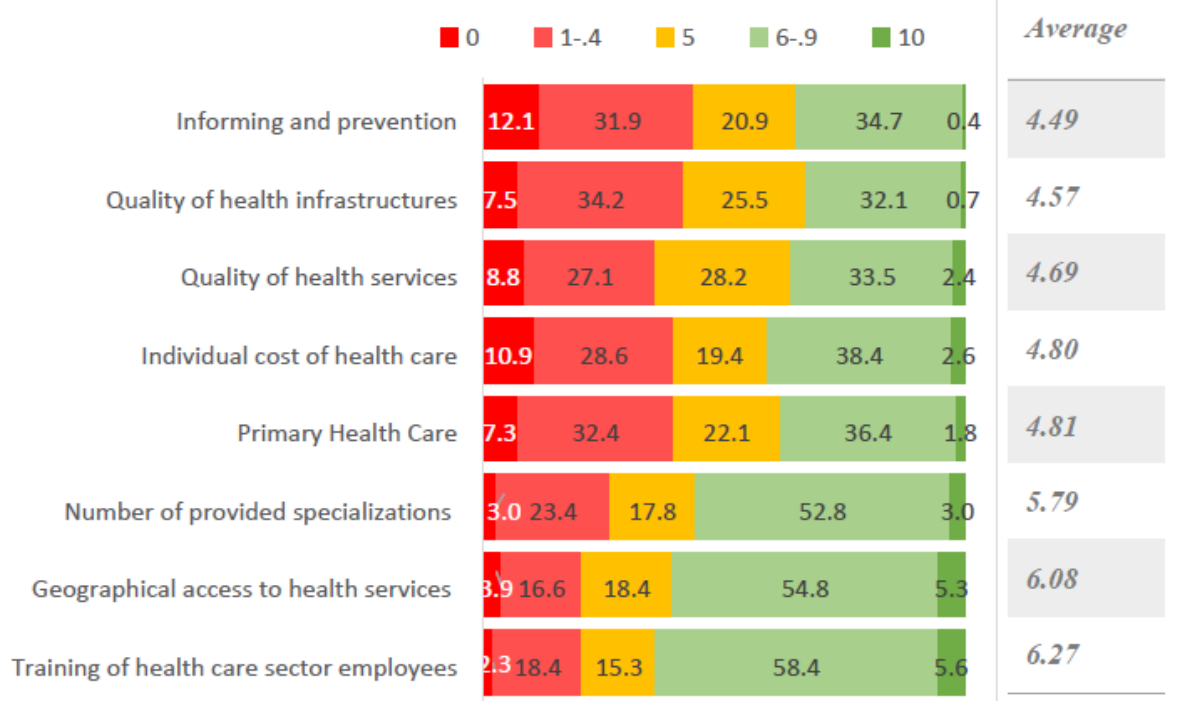

Source: [22] Authors' compiled data sets using data from deliverable 3.2c. Available online at: http://governance.soc.uoc.gr/wp-content/uploads/2017/01/D.3.2c.pdf

Exploring the degree of priority that citizens attach to each of the policy parameters in the field of health care, the need to create a social protection and care network for vulnerable population groups is clearly highlighted. Specifically, the parameters concerning social care and care for medical-pharmaceutical coverage of vulnerable social groups show the highest averages, while the Priority Indicator $(+52 \%$ and $+55 \%$ respectively) is significantly higher than in all other parameters. Moderate priority is given to the use of research and innovation to improve health services, to the introduction of new ways of providing health services and to the promotion of mental health, while human resource development and the introduction of assessment and accountability systems are low priority factors. Finally, the development of medical tourism is positive but show almost zero intensity and the reassignment of health units to needs is negative, which is in line with the relatively high degree of satisfaction of the citizens from geographical access to health infrastructure. 


\section{Figure 4: Proposed political priorities on the health care sector at the Region of Crete}

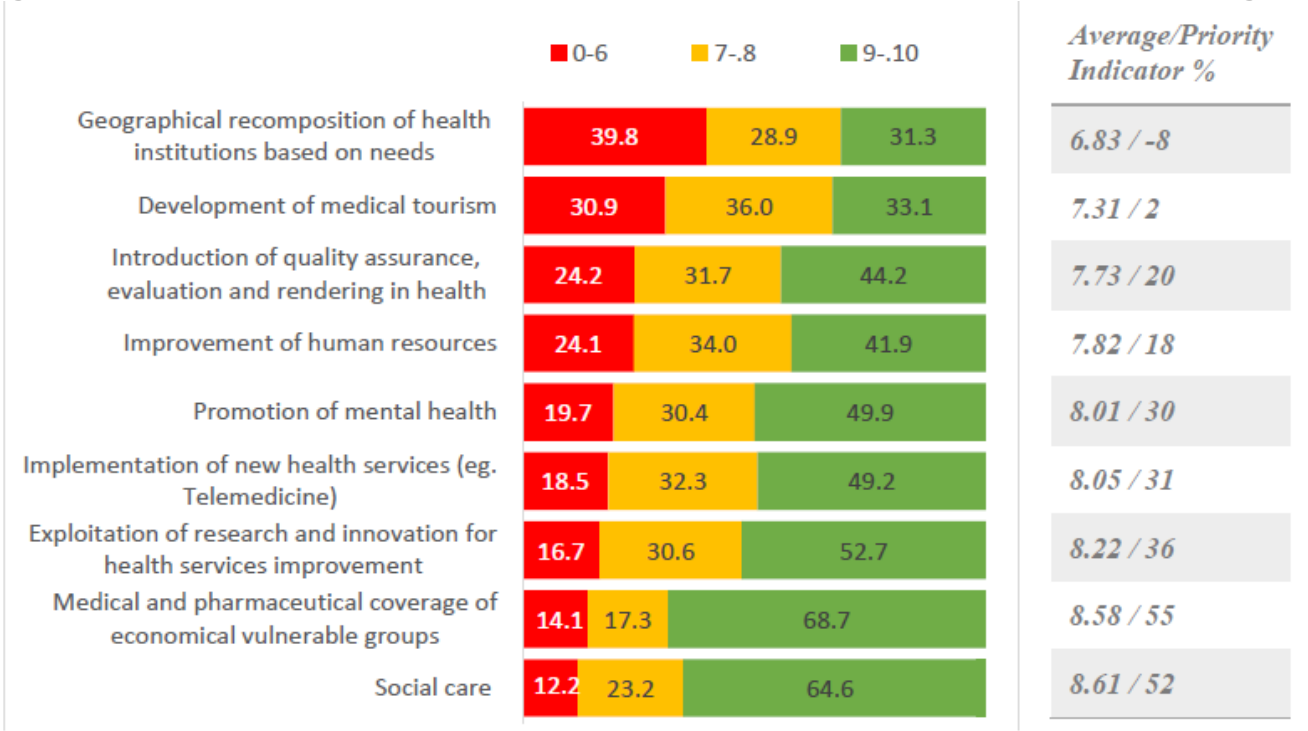

Source: [22] Authors' compiled data sets using data from deliverable 3.2c. Available online at: http://governance.soc.uoc.gr/wp-content/uploads/2017/01/D.3.2c.pdf

Agricultural production is one of the main development pillars of the regional-local economy and therefore, it is necessary to strengthen the areas where lags are indicated. The three areas with the highest average satisfaction are; the promotion of local Cretan products, the effectiveness of product authentication processes and the income from agricultural activities. However, at a much lower rate of satisfaction is the support for export activity, the speed of completion of procedures related with public institutions and, finally, the function of producers' associations / cooperatives which is definitely a factor that is also involved in export activity. Therefore, there is a need to intervene in the sectors linking production with manufacturing and marketing as well as reducing bureaucratic procedures in order to improve the export efficiency of local products.

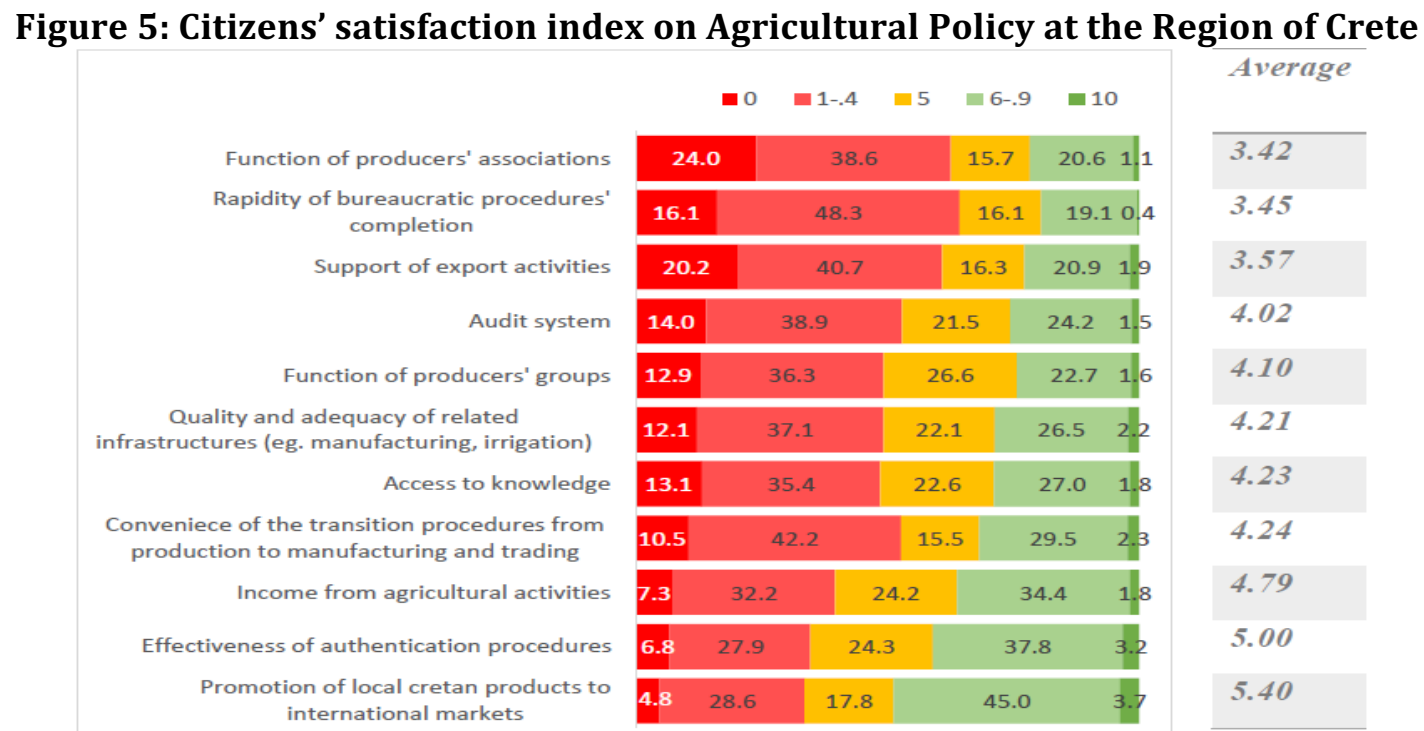

Source: [22] Authors' compiled data sets using data from deliverable 3.2c. Available online at: http://governance.soc.uoc.gr/wp-content/uploads/2017/01/D.3.2c.pdf

All concerns proposed in the field of Agricultural Policy, especially at the level of political strategy of the Region of Crete, receive relatively high priority. This shows the importance of 
this sector in the economic and professional life of the region and the response of the existing regional planning to citizens' needs. As a first priority, the promotion of local Cretan products emerges, as it is directly linked with the surplus value of agricultural products and, consequently, with the income from agricultural activities. The reorganization of unions / associations and the promotion of producers' groups in key Cretan products seems to be a priority both because of the current poor structure of the sector and because of the cumulative power it gives to the producer amid a highly competitive environment. The least priority is given to the promotion of spatial planning and agricultural land-planning, however, it should not be underestimated that these factors are decisive for the development of the touristic sector, as demonstrated by the findings of the qualitative research.

Figure 6: Proposed political priorities on agricultural policy at the Region of Crete

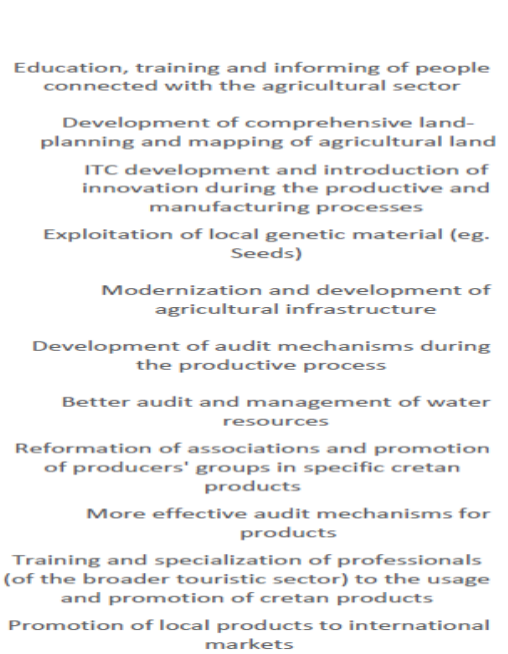

\begin{tabular}{|c|c|c|}
\hline 10.6 & & -10.8 \\
\hline 20.4 & 26.3 & 53.3 \\
\hline 21.2 & 32.6 & 46.2 \\
\hline 19.4 & 25.5 & 55.1 \\
\hline 18.4 & 27.7 & 53.9 \\
\hline 15.4 & 28.8 & 55.8 \\
\hline 14.7 & 30.9 & 54.4 \\
\hline 17.5 & 23.5 & 59.0 \\
\hline 14.9 & 23.4 & 51.7 \\
\hline 14.1 & 33.3 & 52.5 \\
\hline 13.2 & 30.6 & 56.2 \\
\hline 6.8 & 21.0 & 72.1 \\
\hline
\end{tabular}

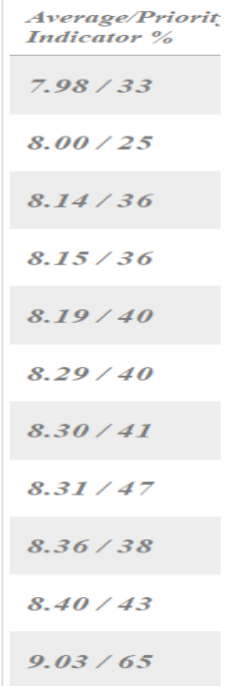

Source: [22] Authors' compiled data sets using data from deliverable 3.2c. Available online at: http://governance.soc.uoc.gr/wp-content/uploads/2017/01/D.3.2c.pdf

At the level of environmental policy, the vast majority of citizens appear unsatisfied in several of the specified parameters. It is clear that no average exceeds the mean value of the scale (5), while relatively large percentages appear at its low end (0). The highest levels of dissatisfaction include the major environmental problems of the region and the effectiveness of environmental inspections and audits, highlighting the need for local and central policy intervention to enable citizens to acquire the necessary knowledge and information and to strengthen the audit capability. 
Figure 7: Citizens' satisfaction index on Environmental Policy at the Region of Crete

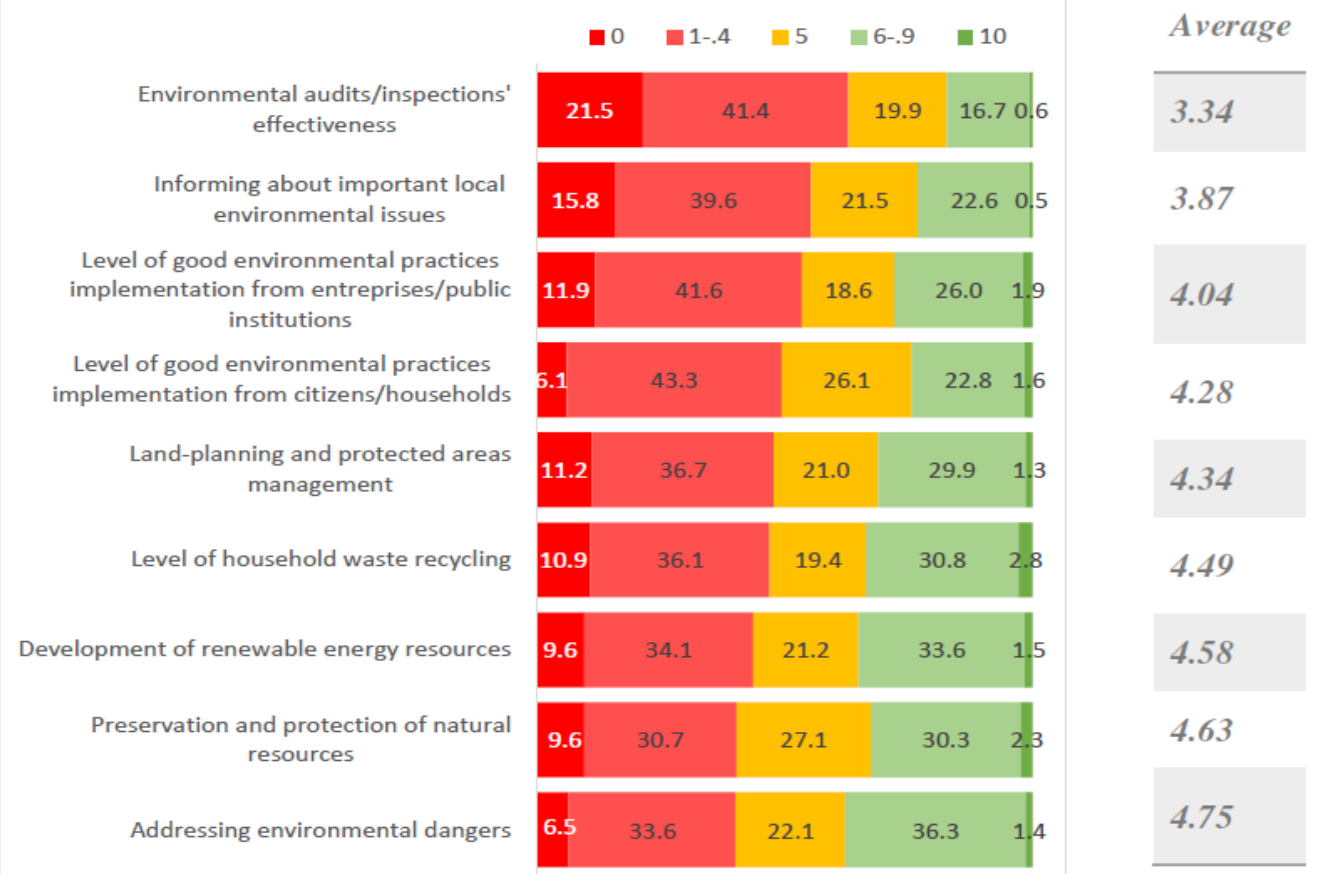

Source: [22] Authors' compiled data sets using data from deliverable 3.2c. Available online at: http://governance.soc.uoc.gr/wp-content/uploads/2017/01/D.3.2c.pdf

Reflecting the low level of satisfaction with environmental policy, the proposed policy initiatives at the level of strategic planning of the Region of Crete are necessary, showing, consequently, a high priority. The highest level of priority is given to the effective management of urban, industrial and hazardous-dangerous waste, while close to the same intensity is the protection and proper management of natural resources and biodiversity, strengthen of the citizens' and enterprises' responsibility towards environmental issues, strengthen of research and innovation in the fields of environment and energy, urban environmental friendly development, environmental hazards, and promotion-support of industrial practices that implement environmentally friendly practices. The lower priority is given to the promotion of urban land-planning as well as to the renewable energy resources and coproduction. However, it should be noted that the Priority Indicator shows medium to high intensity. 
Figure 8: Proposed political priorities on environmental policy at the Region of Crete

\begin{tabular}{|c|c|c|c|c|}
\hline & $\boldsymbol{\square} 0$ & 7-.8 & a-.10 & $\begin{array}{l}\text { Average/Priority } \\
\text { Indicator } \%\end{array}$ \\
\hline $\begin{array}{l}\text { Promotion of renewable energy resources } \\
\text { and coproduction }\end{array}$ & 17.9 & 33.1 & 49.0 & $7.92 / 31$ \\
\hline $\begin{array}{l}\text { Comprehensive implementation of land and } \\
\text { urban planning }\end{array}$ & 17.7 & 39.7 & 42.5 & $7.94 / 25$ \\
\hline $\begin{array}{l}\text { Promotion and support of environmental } \\
\text { friendly industries }\end{array}$ & 16.5 & 32.0 & 51.5 & $8.15 / 35$ \\
\hline Environmental dangers addressing & 16.2 & 33.4 & 50.5 & $8.17 / 34$ \\
\hline Environmental friendly urban development & 15.0 & 33.2 & 50.8 & $8.21 / 37$ \\
\hline $\begin{array}{l}\text { Enhancement of research and innovation in } \\
\text { the environmental and energy sectors }\end{array}$ & 16.0 & 33.5 & 50.5 & $8.23 / 34$ \\
\hline $\begin{array}{l}\text { Enhancement of citizens' and industries' } \\
\text { responsibility towards the environment }\end{array}$ & 14.2 & 31.1 & 54.7 & $8.33 / 41$ \\
\hline $\begin{array}{l}\text { Protection and proper management of } \\
\text { natural resources and biodiversity }\end{array}$ & 13.9 & 27.6 & 58.6 & $8.41 / 45$ \\
\hline $\begin{array}{l}\text { Effective management of urban, industrial } \\
\text { and dangerous waste }\end{array}$ & 127 & 19.9 & 67.3 & $8.46 / 55$ \\
\hline
\end{tabular}

Source: [22] Authors' compiled data sets using data from deliverable 3.2c. Available online at: http://governance.soc.uoc.gr/wp-content/uploads/2017/01/D.3.2c.pdf

It should also be stressed out that for the majority of respondents, the lack of modern infrastructure (e.g. airports, modern highways) is an inhibiting factor for the further development and strengthening of tourism in Crete, as well as for the improvement of life quality. Particular focus is given to the poor condition and the danger of the road network, as long as $87 \%$ of the Cretans appear indifferent to the condition of the island's road network and, above all, of the Northern Highway of Crete (BOAK) which they consider dangerous and unacceptable for an island with high levels of tourism. Although most of the previous issues raised by citizens are related to structural inefficiencies in the response of the Central State to existing major problems in Crete, the intensity expressed from the citizens, can indisputably be used as a pressure lever of the Region of Crete towards the Central State authorities for the implementation of more effective solutions.

Figure 9: Citizens' satisfaction with road infrastructure at the Region of Crete

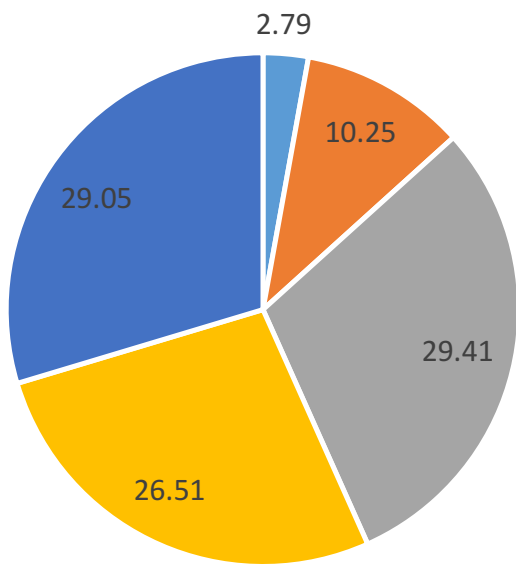

- Extremely - Very - Moderately - Slightly - Not at all

Source: Authors' compiled data sets using data from deliverable 2.4. Available online at: http://governance.soc.uoc.gr/wp-content/uploads/2017/01/D.2.4 See also [23] 
In conclusion, based on the above-mentioned findings, it turns out that the current economic downturn has caused a general dysfunction in the local community, by increasing the problems on specific policies' implementation. Consequently, it is more necessary than ever to develop an integrated and empirically based strategic framework to promote and enhance regional growth that will assist to the improvement of citizens' socio-economic indicators. This plan should include a strategy which should aim at strengthening the core social policy pillars such as health care as well as the environmental and the agricultural pillars. The ultimate aim should be to improve the living conditions and address social problems, promote economic growth, increase employment prospects and simultaneously protect the environment through public interventions as well as enhancing citizens' knowledge.

\section{SYNTHETIC ANALYSIS}

The outcomes of the primary qualitative and quantitative research revealed numerous crucial issues regarding the needs and problems at the Region of Crete related to the fields of governance and sustainable development, as well as to the connection of regional and central policies. Specifically:

i. Competitiveness of Regional Economy: Our analysis shows that Crete has a number of competitive advantages but appropriate concerted approach should be taken to utilize the necessary regulatory actions in order to overcome the structural and bureaucratic problems and to establish effective cooperation and coordination between all actors in order to prioritize and find beneficial solutions. It also emphasizes on the necessity for effective cooperation between the primary sector of the economy and the touristic sector in order to accomplish better promotion for the local products.

ii. Citizens' Satisfaction from Public Policies: The findings show that citizens are highly disappointed with the implemented public policy at the level of the central government. The main reason include the austerity measures which were actually implemented during the economic crisis as well as the failure of the central administration to find solutions to issues related to social development, entrepreneurship and welfare. On the contrary, there was clear satisfaction with the level of regional policy implementation and strategic planning. However, the above-mentioned disappointment often overlooks the remarkable efforts of the Region of Crete.

iii. Health Sector: Based on the results, it appears that there is relatively high satisfaction with the provision of the Primary Health Care services, geographical access to health infrastructure and training of human resources. However, this is overshadowed by the apparent shortages in the infrastructures and by the lack of further development of the human resources on health units. In addition, it turns out that the cost of participation in health sector affects the high priority which should be given to the creation of a comprehensive healthcare network for vulnerable social groups.

iv. Environmental Policies and Renewable Energy Sources: The results of our analysis show the necessity to maintain environmental sustainability and to promote actions and strategies that will contribute to the protection and optimal use of natural resources. In this sense, the expressed anxiety of respondents is expressed by the limited satisfaction on the current environmental policies at national and regional level, and by the lack of information and training both of the citizens and some of the institutional actors' representatives, as regards to environmental issues and renewable energy sources.

v. Agricultural Policy: The participants expressed their dissatisfaction about the general functioning of the central state in terms of agricultural production process reinforcement and strengthening the promotion of agricultural products. The main causes include the extensive bureaucracy, inadequate export support, the inefficient system of inspections and audits, the grinding authentication process and the lack of infrastructure. However, citizens acknowledge that efforts have been made, especially 
at regional level, in order to promote agricultural products and advocate their continuation and further strengthen as priority, underlining as well the necessity of agricultural associations' restructuring.

vi. The Touristic Sector: Tourism is the most important sector of the Cretan economy. The quantitative and qualitative findings have shown that the touristic sector in the Region of Crete is at better level than in the other Greek regions, while actions to promote the international image of Crete seems to be satisfactory. However, as the research findings suggest, there is room for further improvement in the field of Cretan tradition and gastronomy promotion as well as in the infrastructures, in order to enhance the image and the constituent components of the "brand name" of the island. In order such a strategy to be considered as feasible, there should be close cooperation of the touristic sector with the primary economic sector in order to find mutually beneficial solutions.

vii. The Institutional Framework of Regional Governance: It is widely accepted that the modernization of the administrative model of local government, implemented through the 'Kallikratis' project, has produced positive results in terms of effectively solving local problems and needs. However, the findings from the analysis of the qualitative and quantitative data revealed some important problems related both to the lack of resources and to the overlap as well as vague allocation of responsibilities between the regional units and central regional services.

viii. Regional Governance in Crete: Based on the results, it appears that citizens have a significantly higher rate of satisfaction in a wide range of regional policy areas rather than of the central government. Particularly, the skills of the regional staff are assessed more positively. However, the necessity which is expressed by the respondents in the qualitative research include the implementation of continuing training and education programs in the new technologies, the management of European programs and the (further) development of administrative and social skills. On the other hand, civil society associations do not seem to be able to respond adequately to an enlarged social and intervening role, due to the serious economic problems that people encounter. Despite the efforts by the regional agencies, which appear to have made a significant contribution, it is not possible the gaps at the level of social policy to be completely covered by the local and regional authorities, especially after seven years of continuing economic crisis and austerity which has increased social needs and reduced public funds. Furthermore, the respondents of the qualitative research stress out that it is extremely important both central and regional authorities, to introduce new plans for the construction of important infrastructures such as roads, highways and ports, as well as for the renovation and improvement of the existing ones. They propose that their funding could use European funds as well as private investors through partnerships or concessions. Additionally, strengthening the role of social dialogue in Crete, will enable a real self-governing region, capable of producing resources and having its own revenues. At the same time, the utilization of the scientific knowledge for the diagnosis of needs assessment in the fields of tourism and other sectors, promoted and supported by the region of Crete, constitute a potential contributor for sustainable development.

\section{POLICY PROPOSALS AND CONCLUSIONS}

From the comprehensive analysis of the quantitative and qualitative research results a set of policy proposals has been constructed, which aimed at strengthening regional governance, that is a key pillar of governance efficiency improvement as long as it reinforces the implementation of policies that contribute to a faster and more consistent solution to the problems. At the same time, coordination, simplification of bureaucratic procedures and clarification of responsibilities between central and local government, giving emphasis on decentralization, is a policy pillar that promotes the effectiveness of policies for the benefit of 
local and regional societies and economies. In addition, within this framework, training and education of local government officials becomes critical. This criticality is even more remarkable given the importance of these actions, but also the impact they have on efficiency and the improvement of their professional competence, improving both the existing human capital and the conditions for its development [24].

It should also be noted that the main objective of local governance should be the improvement of social well-being, in order to efficiently address crucial social problems and cover the gaps of the central public policy in terms of social protection. Therefore, efforts that could support social development and integrate the socially vulnerable should be enhanced by local and regional authorities, as the respondents in the qualitative research point out. As a result, they are highlighted as key priorities not only because of their multidimensional and structural importance for the well-being of society, but also because of the apparent weakness of the central state in coping with negative social consequences of the economic crisis. These interventions could also help strengthening civil society, social entrepreneurship and corporate social responsibility.

Finally, an equally important priority is to promote and support local entrepreneurship. This sector in the Region of Crete is multi-level, because it involves the touristic sector as well as the promotion of the products of the primary sector. With the aim of the development of these economic pillars, it turns out that the starting point should be to align them with the principles of sustainable development and the use of renewable energy sources.

\section{ACKNOWLEDGEMENTS}

We would like, hereby, to thank Prof. Vaggelis Tzouvelekas (Department of Economics, UoC), Prof. Vassilis Dafermos (Department of Political Science, UoC), Dr Panos Liverakos (UNDP), Dr Kostis Pigounakis (Department of Economics, UoC), Periklis Drakos (Department of Economics, UoC) and Marinos Chourdakis (PhD Candidate, Department of Political Science, UoC), for their valuable contribution on the analysis of some of the research key findings and subsequently on the Ch. 5 of the present paper.

\section{References}

\section{G: in Greek}

Papadakis, N., \& Lavdas, K., Governance and Sustainability in the Region of Crete. Research, Challenges and Policy proposals, in N. Papadakis \& K. Lavdas, Governance, Sustainability and Innovation at the regional level. 2017, Heraklion: University of Crete Prinitng Centre, 9- 27, p. 11 (G)

Baker, S., Kousis, M., Richardson. D., Young, S., The politics of sustainable development, 2005, London: Routledge.

Holmberg, J., Making Development Sustainable: Redefining Institutions, Policy, and Economics, 1992, Washington, D.C.: Island Press.

Reed, D., Structural Adjustment, the Environment and Sustainable Development, 1997, London: Earthscan Publications.

Harris, J.M., et al., A Survey of Sustainable Development: Social and Economic Dimensions, 2001, Washington, D.C.: Island Press.

Hulse, J., Sustainable development at risk. Ignoring the past, 2007, International Development Research Center, Cambridge University Press India.

Böcher, M., Regional Governance and Rural Development in Germany: the Implementation of LEADER+. European Society for Rural Sociology, 2008. 48 (4): 372-388.

Rhodes, R., The New Governance: Governing without Government. Political Studies, 1996, 44: 652-67.

Storper, M., The regional world: territorial development in a global economy, 1997, London: Guilford Press.

Pierre, J. and B.G. Peters, Governance, Politics and the State, 2000, London: Macmillan Press Ltd. 
Eberlein, B. and D. Kerwer, D., Theorising the new modes of European Union governance. European Integration online Papers (EIoP), 2002, 6 (5).

Punyaratabandhu, S., Commitment to Good Governance, Development, and Poverty Reduction: Methodological Issues in the Evaluation of Progress at National and Local Levels, 2004, Paper for inclusion in the Report of the Sixth Session of the Committee on Development Policy. New York: UN.

Ekins, P., Economic Growth and Environmental Sustainability: the Prospects for Green Growth, 2000, London: Routledge.

Holmberg, J., Making Development Sustainable: Redefining Institutions, Policy, and Economics, 1992, Washington, D.C.: Island Press.

Morgan, K., The learning region: institutions, innovation and regional renewal. Regional Studies. 1997, 31: 491-504.

Mazzonis, D., Small firm networking, cooperation and innovation in Italy: viewed by an agency engaged in actions for stimulating the technological upgrading of industry. Entrepreneurship and Regional Development. 1989, 1 (1): 6174

Moussis, N., European Union, Law, Economy, Policy, 2015, Athens: Papazisis Publications [in Greek].

Ketola, E. and M. Klockars, Computer-assisted telephone interview (CATI) in primary care. Family Practice. 1999, (16):179-183.

Wright, K. B., Researching Internet-Based Populations: Advantages and Disadvantages of Online Survey Research, Online Questionnaire Authoring Software Packages, and Web Survey Services. 2005, Journal of Computer-Mediated Communication 10

Leung, S. O., A Comparison of Psychometric Properties and Normality in 4-, 5-, 6-, and 11-Point Likert Scales. 2011, Journal of Social Service Research, 37: 412-421.

Bertelsmann Stiftung, Social Justice in the EU - Index Report 2017. Social Inclusion Monitor Europe, 2017, Gütersloh: Bertelsmann Stiftung.

Drakos, P., Pigounakis, K., Tzouvelekas, V., Research Findings and Conclusions on the regional policy at the domains of Agriculture, Health and Environment, in N. Papadakis \& K. Lavdas, Governance, Sustainability and Innovation at the regional level. 2017, Heraklion: University of Crete Prinitng Centre, 28- 55, p. 36, 39, 49, 51, 43, $45(\mathrm{G})$

Dafermos, V., Basic Factors of the Development of the Touristic Product in Crete, in N. Papadakis \& K. Lavdas, Governance, Sustainability and Innovation at the regional level. 2017, Heraklion: University of Crete Prinitng Centre, 56- 62, p. 59 (G)

Drakaki, M., Papadakis, N., Liverakos, P., Good Governance and Sustainability in Local Administration: Transversal skills' development, in N. Papadakis \& K. Lavdas, Governance, Sustainability and Innovation at the regional level. 2017, Heraklion: University of Crete Prinitng Centre, 96- 121. (G) 